\title{
TRYPSIN-MEDIATED MODIFICATION OF THE ZONA PELLUCIDA GLYCOPEPTIDE STRUCTURE OF HAMSTER EGGS
}

\author{
T. OIKAWA, ${ }^{*}$ G. L. NICOLSON† AND R. YANAGIMAGHI* \\ * Department of Anatomy and Reproductive Biology, University of Hawaii \\ School of Medicine, Honolulu, Hawaii 96822, and †Cancer Council and \\ Electron Microscopy Laboratories, The Salk Institute for Biological Studies, \\ San Diego, California 92112, U.S.A.
}

(Received 30th August 1974)

One of the mechanisms that prevents polyspermy in mammals is the zona reaction, which involves a modification of the zona pellucida (Braden, Austin \& David, 1954; Austin, 1961). Cortical granules have been implicated in this process because upon stimulation or fertilization of the egg they release a substance(s) which acts on the zona and renders it impenetrable to spermatozoa (Austin \& Braden, 1956; Barros \& Yanagimachi, 1971). Gwatkin, Williams, Hartmann \& Kniazuk (1973) have proposed that the zona reaction is mediated by a trypsin-like protease released from the cortical granules which attacks the zona sperm-receptors. Vacquier, Tegner \& Epel $(1972,1973)$ have proposed a similar mechanism for the block to polyspermy in invertebrate eggs. We report here that low concentrations of crystalline trypsin modify the glycopeptide structure of the zona pellucida, and this modification is detected by plant lectins.

Mature unfertilized eggs of the golden hamster were obtained as follows. Adult hamster females were each injected intraperitoneally with 20 to 30 i.u. PMSG in the morning ( 09.00 to 11.00 hours) of Day 1 (day of ovulation) of the oestrous cycle followed by an intraperitoneal injection of 20 to 30 i.u. HCG in the afternoon or evening ( 15.00 to 22.00 hours) of Day 3 of the oestrous cycle. Between 15 and $17 \mathrm{hr}$ after injection of HCG, the animals were killed and their oviducts were flushed with Tyrode's solution containing $0.1 \%$ crystalline bovine serum albumin (Reheis Chem. Co., Chicago, U.S.A.) (TA). The eggs were freed from the surrounding cumulus cells by treatment for $15 \mathrm{~min}$ at $25^{\circ} \mathrm{C}$ with $0.1 \%$ bovine testicular hyaluronidase (300 USP units per mg; Nutritional Biochem. Corp., Cleveland, U.S.A.) in TA. To obtain fertilized eggs at the pronuclear stage, females were treated with PMSG and HCG as above. About $7 \mathrm{hr}$ after injection of HCG, spermatozoa from the cauda epididymidis were suspended in TA and inseminated directly into the uterus. The oviducts were flushed with TA $16 \mathrm{hr}$ later. Treatment of fertilized eggs with hyaluronidase was unnecessary since the cumulus cells had dispersed by the time of recovery. Unfertilized and fertilized eggs were rinsed with TA and each type was separated into two groups. The eggs in one group of each type were treated for 5 to $120 \mathrm{~min}$ at $25^{\circ} \mathrm{C}$ with $0.0001 \%$ or $0.001 \%$ bovine pancreatic trypsin (twice crystallized, Type III, 
10,000 to 13,000 BAEE units/mg; Sigma Chem. Co., Saint Louis, U.S.A.) in $0.01 \mathrm{M}$-tris-HCl: $0.9 \% \mathrm{NaCl}: 0.1 \%$ crystalline albumin ( $\mathrm{pH} 7.4$ ) containing 100 $\mu \mathrm{g} / \mathrm{ml}$ affinity purified wheat germ agglutinin (WGA) (Burger \& Goldberg, 1967), or with Ricinus communis agglutinin with a molecular weight of 120,000 (RGAI) (Nicolson \& Blaustein, 1972), or with Dolichos biflorus agglutinin (DBA) (Etzler \& Kabat, 1970). After incubation for $30 \mathrm{~min}$ in one of the lectin solutions at $25^{\circ} \mathrm{C}$, the eggs were tested for (a) the ability to agglutinate through their zonae pellucidae and (b) changes in the light-scattering properties of their zonae pellucidae (Oikawa, Yanagimachi \& Nicolson, 1973; Oikawa, Nicolson \& Yanagimachi, 1974). For the agglutination experiments, the eggs in a lectin solution were aggregated by pushing about ten of them together with a needle. The dishes were then agitated to disperse the aggregates. Agglutination was qualitatively scored +++ when all the eggs remained firmly attached through their zonae despite repeated agitation (Pl. 1, Fig. 1), ++ when the eggs dispersed into two or three aggregates of three to six eggs each, + to \pm when the aggregates contained only two to three eggs each, and - when the eggs completely dispersed (Pl. 1, Fig. 2). Light scattering of the zona pellucida was scored + when the outermost surface of the zona scattered light strongly under dark-field illumination (Pl. 1, Fig. 3), and \pm or - when there was little or no light scattering (Pl. 1, Fig. 4) (Oikawa et al., 1973, 1974). The other group of eggs (control) was treated in the same manner except for the omission of the trypsin pretreatment or for the inclusion of lectin saccharide inhibitors in the lectin solutions.

In another series of experiments, the ability of trypsin pretreatment to render the zona pellucida of unfertilized eggs impenetrable to spermatozoa was examined. The unfertilized eggs (freed from the cumulus cells) were treated for 5 to 120 min with $0.0001 \%$ or $0.001 \%$ trypsin as described above. The eggs were thoroughly rinsed with TA and exposed in vitro to capacitated spermatozoa which had undergone an acrosome reaction (Oikawa et al., 1973, 1974). Two hours later, the eggs were examined with a phase-contrast microscope for sperm attachment and evidence of sperm penetration into or through the zona pellucida. The eggs (zonae) were recorded as unpenetrated if spermatozoa were attached to the surface but none was within or through the zona.

When hamster eggs were treated with lectins without pretreatment with trypsin, they agglutinated strongly ( $\mathrm{RCAI}$ ), moderately (DBA) or not all (WGA) (Table 1, Exps 1 and 8). Eggs treated with lectin showed strong light scattering from the zona surface (Table 1, Exps 1 and 8). These lectin-induced properties were specific because inclusion of the appropriate saccharide inhibitors, e.g. $0 \cdot 1 \mathrm{~m}$-lactose for RGAI, $0 \cdot 1 \mathrm{M}-\mathrm{N}$-acetyl-D-galactosamine for DBA and $0.1 \mathrm{M}-\mathrm{N}$-acetyl-D-glucosamine for WGA, abolished these effects. Pretreatment of unfertilized eggs with trypsin inhibited sperm penetration of the zona (Table 1, Exps 2 to 5 and 7). It also increased the ability of eggs to agglutinate with WGA, but not with RCAI or DBA (Table 1, Exps 5 and 7). The trypsininduced increase in agglutination with WGA could be blocked by the addition of soybean trypsin inhibitor (Type I-S, Sigma Chemical Co., Saint Louis, U.S.A.) (Table 1, Exp. 6). Pretreatment with trypsin also prevented lectins from inducing light scattering from the zona (Table 1, Exps 4, 5, 7 and 9). 


\section{PLATE 1}
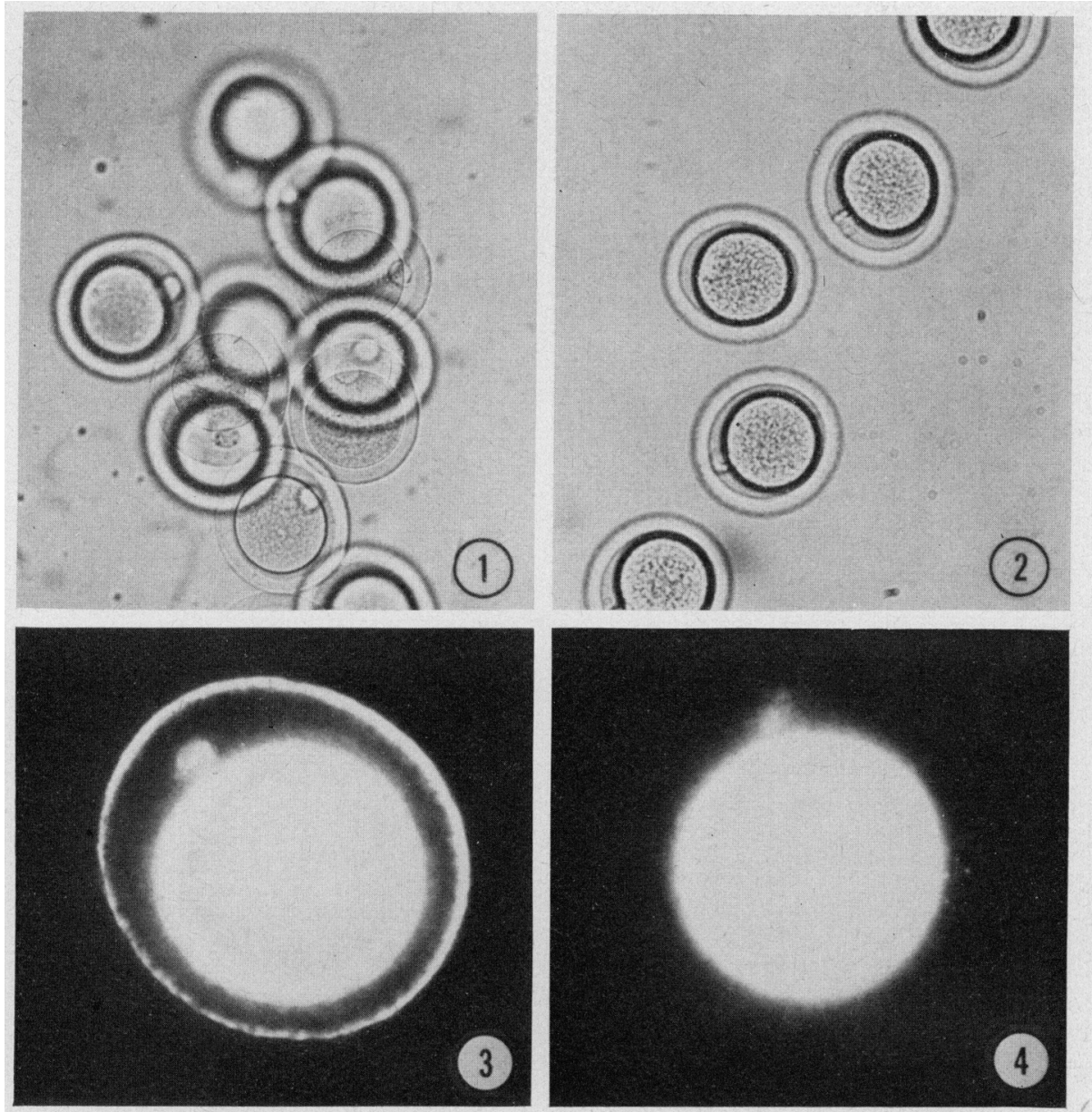

FIG. 1. Unfertilized hamster eggs strongly agglutinated $(+++)$ by RG.AI. $\times 130$.

FIG. 2. Unfertilized hamster eggs that failed to agglutinate by RCAI in the presence of a saccharide inhibitor, $0 \cdot 1 \mathrm{~m}$-lactose. $\times 130$.

Fic. 3. Strong light scattering $(+)$ of the outermost region of the zona pellucida of a hamster egg treated with RCAI. Dark-field, $\times 420$.

Fig. 4. Absence of light scattering of the outer region of the zona pellucida when a hamster egg was treated with RGAI in the presence of a saccharide inhibitor, $0 \cdot 1$ M-lactose. Dark-field, $\times 420$. 


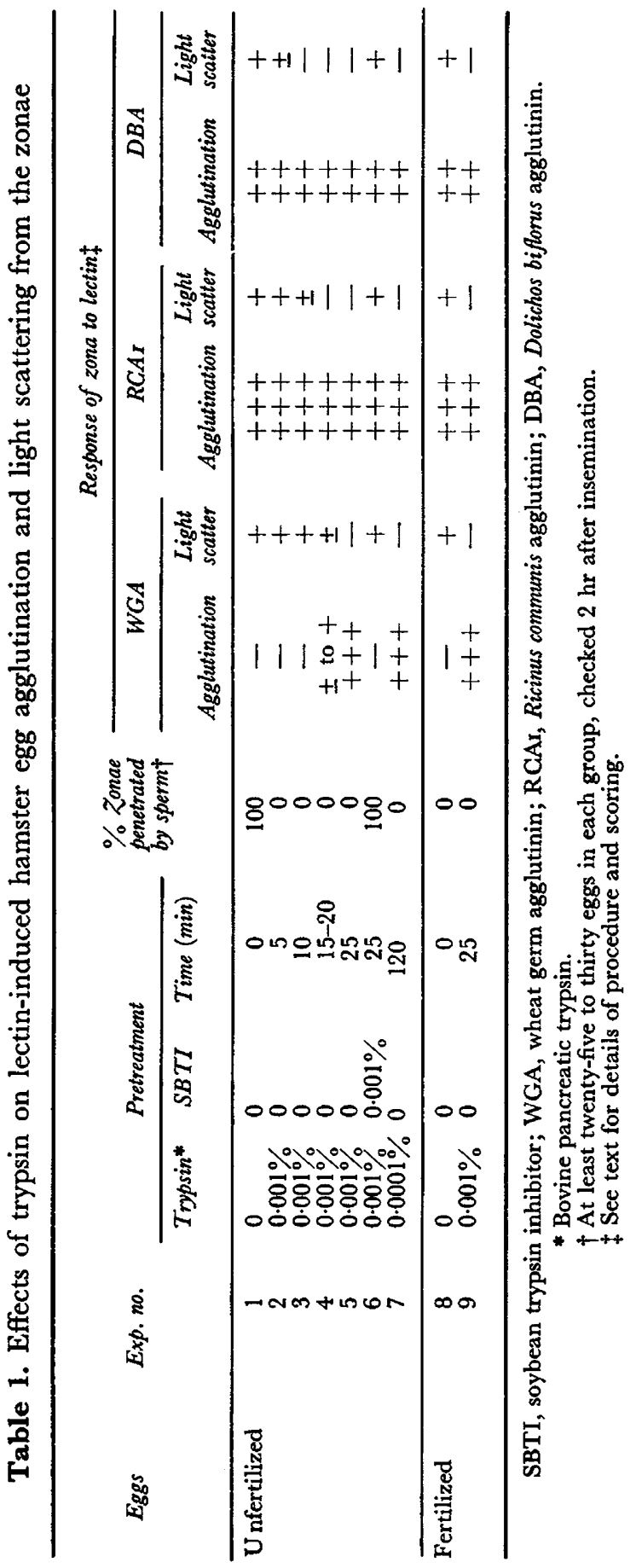


In contrast to the effects of trypsin, fertilization of hamster eggs in vivo did not result in an increase in egg agglutination with WGA or prevent lectin from inducing light scattering, but it did block sperm penetration through the zona (Table 1, Exp. 8).

The results indicate that trypsin treatment such as that employed by Hartmann \& Gwatkin (1971), e.g. $0.0001 \%$ for $120 \mathrm{~min}$ at $25^{\circ} \mathrm{C}$; Table 1, Exp. 7, results in zona modifications that are not found after fertilization in vivo. Thus, the zona reaction mediated by fertilization may be different from the block to fertilization induced by trypsin. These experiments do not rule out the possibility that very brief trypsin treatment (see Table 1, Exp. 2) may actually mimic the native zona reaction. The possibility also exists that fertilization results in the release of other non-protease enzymes (such as glycosidase or glucanase) similar to those found by Epel, Weaver, Muchmore \& Schimke (1969) in sea urchin eggs. Under physiological conditions, protease(s), and possibly other enzymes such as glycosidases, may jointly alter the zona pellucida to prevent sperm binding and penetration. The blocking of sperm penetration by purified trypsin alone may be due to proteolytic destruction of the zona pellucida, and may not reflect the natural mechanism of the zona reaction.

This work was supported by grants from the Population Council, the Ford Foundation, U.S. Public Health Service (HD-03402) (R.Y.) and the National Science Foundation (GB-34178) to one of us (G.L.N.). We thank Mrs G. A. Mahi for her assistance in preparation of the manuscript.

\section{REFERENGES}

Austin, C. R. (1961) The Mammalian Egg. C. C. Thomas, Springfield, Illinois.

Austin, C. R. \& BRADEN, A. W. H. (1956) Early reactions of rodent egg to spermatozoon penetration. 7. exp. Biol. 33, 358-365.

Barros, C. \& YANAGIMACHI, R. (1971) Induction of zona reaction in golden hamster eggs by cortical granule material. Nature, Lond. 233, 268-269.

Braden, A. W. H., Austin, C. R. \& David, H. A. (1954) The reaction of the zona pellucida to sperm penetration. Aust. F. biol. Sci. 7, 391-409.

BURger, M. M. \& Goldberg, A. R. (1967) Identification of a tumor-specific determinant on neoplastic cell surfaces. Proc. natn. Acad. Sci. U.S.A. 57, 359-366.

Eped, D., Weaver, A. M., Muchmore, V. \& Schimke, R. T. (1969) $\beta$-1,3-Glucanase of sea urchin eggs: release from particles at fertilization. Science, N.Y. 163, 294-296.

Etzler, M. E. \& Kabat, E. A. (1970) Purification and characterization of a lectin (plant hemagglutinin) with blood group A specificity from Dolichos biforus. Biochemistry, 9, 869-877.

Gwatkin, R. B. L., Williams, D. T., Hartmann, J. F. \& Kniazux, M. (1973) The zona reaction of hamster and mouse eggs: production in vitro by a trypsin-like protease from cortical granules. 7. Reprod. Fert. 32, 259-265.

Hartmann, J. F. \& Gwatkin, R. B. L. (1971) Alteration of sites on the mammalian sperm surface following capacitation. Nature, Lond. 234, 479-481.

Nicolson, G. L. \& Blaustern, J. (1972) The interaction of Ricinus communis agglutinin with normal and tumor cell surfaces. Biochim. biophys. Acta, 266, 543-547.

Orkawa, T., Nicolson, G. L. \& Yanagimachi, R. (1974) Inhibition of hamster fertilization by phytoagglutinins. Expl Cell Res. 83, 239-246.

Orkawa, T., Yanagrmachi, R. \& Nicolson, G. L. (1973) Wheat germ agglutinin blocks mammalian fertilization. Nature, Lond. 241, 256-259.

Vacquier, V. D., Tegner, M. J. \& Epel, D. (1972) Protease activity establishes the block against polyspermy in sea urchin eggs. Nature, Lond. 240, 352-354.

VAceuter, V. D., Tegner, M. J. \& EPEL, D. (1973) Protease releases from sea urchin eggs at fertilization and alters the vitelline layer and aids in prevention of polyspermy. Expl Cell Res. 80, 111-119. 